\title{
The role of calcium (source \& content) on the in vitro behaviour of sol-gel quaternary glass series
}

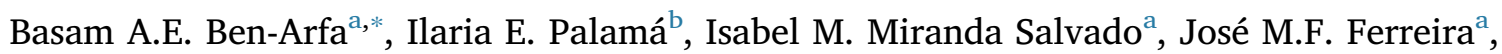 \\ Robert C. Pullar ${ }^{\mathrm{a}}$ \\ ${ }^{a}$ Department of Materials and Ceramic Engineering, CICECO - Aveiro Institute of Materials, University of Aveiro, 3810-193, Aveiro, Portugal \\ ${ }^{\mathrm{b}}$ CNR NANOTEC, Istituto di Nanotecnologia, Campus Ecotekne, Via Monteroni, 73100, Lecce, Italy
}

\section{A R T I C L E I N F O}

\section{Keywords:}

Bioactive glasses

Biocompatibility

$\mathrm{Ca} / \mathrm{P}$ ratio

High silica content

Sol-gel derived glass

In vitro MTT tests

\begin{abstract}
A B S T R A C T
To highlight the effect of salt precursors on the final properties, bioactivity and biocompatibility, five quaternary (Si-Ca-P-Na) glass compositions were successfully prepared through two distinct rapid sol-gel routes; one using acetate salt precursors (A) catalysed by nitric acid, and the other using nitrate salts (N) and citric acid as a catalyst. The sols dried rapidly, and stabilised at $550 \& 800^{\circ} \mathrm{C}$ to be characterised by X-ray diffraction (XRD), Magic angle spinning-Nuclear magnetic resonance $\left({ }^{29} \mathrm{Si}\right.$ MAS-NMR) and Fourier transform infra-red spectroscopy (FTIR). Upon immersion in simulated body fluid (SBF), hydroxyapatite (HAp) formation was initially enhanced by increasing Ca-content up to $40 \mathrm{~mol} \%$, but the formation of calcite was favoured with further increments of Ca to 45 and $48 \mathrm{~mol} \%$. The A-glasses exhibited lower density and lower network connectivity compared with $\mathrm{N}$-glasses. The chemical surface modifications after $4 \mathrm{~h}$ in SBF were more evident for $\mathrm{N}-\mathrm{glasses}$ in comparison to A-glasses. The biocompatibility is favoured for the samples treated at $800{ }^{\circ} \mathrm{C}$ and for the samples of the higher silica contents.
\end{abstract}

\section{Introduction}

The release of calcium ions $\left(\mathrm{Ca}^{2+}\right)$ from bioactive glasses during the in vitro bioactivity assessment in simulated body fluid (SBF) may increase the degree of super saturation of the SBF solution and favour the nucleation of apatite onto the silica gel layer initially formed at the glass surface [1]. To some extent, increasing the calcium (Ca) content in a glass composition tends to enhance porosity (pore volume and diameter), while significantly increasing the skeletal density [2]. However, it was also demonstrated that very high $\mathrm{Ca}$ contents stimulate the preferential formation of calcite $\left(\mathrm{CaCO}_{3}\right)$ over HAp during the SBF immersion tests [3].

In turn, the in vitro bioactivity of bioactive glasses can be favoured by using low $\mathrm{P}_{2} \mathrm{O}_{5}$ contents $(<10 \mathrm{~mol} \%)$, as under these conditions phosphorus acts as network modifier instead of network former. Consequently, greater $\mathrm{P}_{2} \mathrm{O}_{5}$ content increases the network connectivity and exerts an opposite and deteriorating effect on bioactivity [4]. This can be attributed to the high affinity of the modifiers such as calcium and sodium to coordinate with phosphorus, thus enhancing its structural role [5]. This will result in a lower bio-mineralisation rate [6].

The inclusion of calcium and phosphate in the glass system facilitates apatite formation [3]. The $\mathrm{Ca} / \mathrm{P}$ ratio is known to play an important role in modifying and tailoring the bioactivity of glasses. Compositions that enhance the non-bridging oxygens/bridging oxygens (NBO/BO) ratio reduce the glass network structure and connectivity. It has been noted that the inclusion of $\mathrm{Na}_{2} \mathrm{O}$ in bioactive glasses induces a more accentuated glass-network-disrupting effect and maintains a good bioactivity rate. After sintering, biodegradable crystalline phases may formed and the mechanical properties of glass-ceramics may be improved [7].

It is well known that alkoxides are often used as precursors for oxides in sol-gel synthesis [8]. However, alkoxides are not available for all metals, and may be expensive or difficult to handle such as those of group I \& II metals, which are very moisture-sensitive [9-11]. Sometimes alkoxides exist in the solid state, but are difficult to dissolve in many solvents, or may have unreliable purity. Therefore, organic or inorganic acid salts of alkali and alkali earth metals, are common precursors in sol-gel synthesis.

Organic acid metal salts - easily soluble in water, are often used in the form of acetates and citrates [12]. The disadvantages of using acetates are: (a) the high $\mathrm{pH}$ of the solution during sol-gel preparation, which may lead to precipitation and/or a fast gelation of the sol; (b) the

\footnotetext{
* Corresponding author.

E-mail address: basam@ua.pt (B.A.E. Ben-Arfa).
} 
Table 1

Nominal compositions of the Sol-Gel derived glass.

\begin{tabular}{|c|c|c|c|c|c|}
\hline \multirow[t]{2}{*}{ № } & \multicolumn{2}{|l|}{ Designation } & \multicolumn{2}{|l|}{ Composition } & \multirow[t]{2}{*}{$\mathrm{Ca} / \mathrm{P}$} \\
\hline & Acetate & Nitrate & Oxide molar ratios & Cationic ratios & \\
\hline $1 \& 6$ & S67C24-A & S67C24-N & $67 \mathrm{SiO}_{2}-2.5 \mathrm{Na}_{2} \mathrm{O}-24 \mathrm{CaO}-2 \mathrm{P}_{2} \mathrm{O}_{5}$ & $67 \mathrm{Si}-5 \mathrm{Na}-24 \mathrm{Ca}-4 \mathrm{P}$ & 6 \\
\hline $2 \& 7$ & S59C32-A & S59C32-N & $59 \mathrm{SiO}_{2}-2.5 \mathrm{Na}_{2} \mathrm{O}-32 \mathrm{CaO}-2 \mathrm{P}_{2} \mathrm{O}_{5}$ & $59 \mathrm{Si}-5 \mathrm{Na}-32 \mathrm{Ca}-4 \mathrm{P}$ & 8 \\
\hline $3 \& 8$ & S51C40-A & S51C40-N & $51 \mathrm{SiO}_{2}-2.5 \mathrm{Na}_{2} \mathrm{O}-40 \mathrm{CaO}-2 \mathrm{P}_{2} \mathrm{O}_{5}$ & $51 \mathrm{Si}-5 \mathrm{Na}-40 \mathrm{Ca}-4 \mathrm{P}$ & 10 \\
\hline $4 \& 9$ & S49C45-A & S49C45-N & $49 \mathrm{SiO}_{2}-1.5 \mathrm{Na}_{2} \mathrm{O}-45 \mathrm{CaO}-1.5 \mathrm{P}_{2} \mathrm{O}_{5}$ & $49 \mathrm{Si}-3 \mathrm{Na}-45 \mathrm{Ca}-3 \mathrm{P}$ & 15 \\
\hline $5 \& 10$ & S44C48-A & S44C48-N & $44 \mathrm{SiO}_{2}-2 \mathrm{Na}_{2} \mathrm{O}-48 \mathrm{CaO}-2 \mathrm{P}_{2} \mathrm{O}_{5}$ & $44 \mathrm{Si}-4 \mathrm{Na}-48 \mathrm{Ca}-4 \mathrm{P}$ & 12 \\
\hline
\end{tabular}

large amount of catalyst required to promote hydrolysis that remains as residue in the final product, and needs elevated temperatures to be eliminated; (c) the carbonaceous residues in the final products.

Inorganic acid metal salts - are commonly used in sol-gel because they dissolve easily in water, especially in the case of nitrates, and the by-products decompose at relatively moderate temperatures in comparison with sulphates and chlorides [12]. The major disadvantage of using metal nitrate salts is their tendency to crystallise in an uncontrollable manner during aging and drying processes, which negatively affects the homogeneity and the microstructure of the final product. The fast evaporation of a large portion of water at an early stage of sol preparation, i.e. before gelling, tends to suppress the crystallisation [12].

Catalyst - the type of catalyst used affects the final properties, such as porosity, optical and structural properties. Therefore, the selection of catalyst depends on the desired properties of the final product [13]. The catalyst facilitates the hydrolysis of the dissolved metal ions, and affects the hydrolysis and condensation processes as has been well addressed by Brinker and co-workers [14]. Many authors suggest that a given concentration of an inorganic acid is a more effective catalyst than using an equivalent amount of base [14]. The mineral (inorganic) acids such as sulphuric acid, hydrochloric acid and nitric acid are strong, being the most commonly used catalysts, and they trigger the hydrolysis reaction in a very short time [7]. The major drawback of using inorganic acids as catalysts is the increased concentration of their anions in the sample that require higher temperatures for the full elimination of the by-products. However, the increase in the calcination temperature readily converts glasses into glass ceramics 12] ]. As a trial to reduce the inorganic acid concentration in the sol-gel glass, Faure et al. [15] replaced strong inorganic acids $\left(\sim 0.5-2 \mathrm{~mol} \mathrm{~L}^{-1}\right)$ with much lower quantities of weak organic acids $\left(0.5-50 \mathrm{mmol} \mathrm{L}^{-1}\right)$. They successfully used citric acid as a catalyst for the synthesis of $45 \mathrm{~S} 5$ bioactive glass ceramic. The roles of heat treatment temperature [16] and $\mathrm{Ca} / \mathrm{P}$ ratio [17] on the bioactivity and biocompatibility of ternary Sol-Gel glass systems have been well discussed and addressed.

Nevertheless, there is a lack of research combining the role of $\mathrm{Ca} / \mathrm{P}$ ratio, heat treatment temperature, and the source of $\mathrm{Ca}$ and $\mathrm{Na}$ on the microstructure, morphology, bioactivity and biocompatibility of quaternary sol-gel glass systems. Therefore, the aim of this work is to synthesise two series of five different glass compositions. In the 1st route, acetate salts are used as precursors for $\mathrm{Ca}$ and $\mathrm{Na}$, and nitric acid served as catalyst. In the 2 nd route, nitrate salts were used as precursors for $\mathrm{Ca}$ and $\mathrm{Na}$, and citric acid was used as catalyst. In both routes, the $\mathrm{Ca} / \mathrm{P}$ ratio was varied from 6 to 15 . The molar content of the sodium was intentionally kept low, as $\mathrm{Na}^{+}$exhibits a very fast exchange with the $\mathrm{H}^{+}$from SBF, which can lead to an abrupt increase of dissolution rate, and concomitantly to an increase in $\mathrm{pH}$ and a decrease in silica gel re-polymerisation [18]. The alternative use of acetates or nitrates as precursors for $\mathrm{Na}$ and $\mathrm{Ca}$ was systematically explored in this work in an attempt to shed light on their effects on the network structure, bioactivity and biocompatibility of the resulting Sol-Gel derived bioactive glasses. All glass samples were investigated through an array of techniques including: Specific surface area (SSA), skeletal density, particle size distribution, X-ray diffraction (XRD), ${ }^{29} \mathrm{Si}$ magic angle spinning nuclear magnetic resonance (MAS-NMR), scanning electron microscopy (SEM), and energy dispersive spectroscopy (EDS). Moreover, biocompatibility and bioactivity tests were performed.

As far as we are aware, no such systematic study on the synthesis of quaternary bioactive glasses for biomedical applications has been performed previously.

\section{Materials and methods}

\subsection{Glass preparation}

The rapid sol-gel synthesis method developed by the authors [15] was adopted in this work to produce two series of glasses, each one with five different compositions (Table 1). The two different series only differ in the precursor salts for sodium and calcium, and in the catalyst used. In the acetates route, calcium acetate monohydrate (Ca $\left.\left(\mathrm{C}_{2} \mathrm{H}_{3} \mathrm{O}_{2}\right)_{2} \cdot \mathrm{H}_{2} \mathrm{O}, \geq 99.0 \%\right)$ and sodium acetate $\left.\left(\mathrm{Na}\left(\mathrm{C}_{2} \mathrm{H}_{3} \mathrm{O}_{2}\right), \geq 99.0 \%\right)\right)$ were selected as precursors, while nitric acid $\left(\mathrm{HNO}_{3}, \geq 68.0 \%\right)$ was used as catalyst. In the nitrates route, calcium nitrate tetrahydrate ( $\mathrm{Ca}$ $\left.\left(\mathrm{NO}_{3}\right)_{2} \cdot 4 \mathrm{H}_{2} \mathrm{O}, \geq 99 \%\right)$ and sodium nitrate $\left(\mathrm{NaNO}_{3}, \geq 99 \%\right)$ ) were adopted as precursors, and citric acid monohydrate $\left(\mathrm{C}_{6} \mathrm{H}_{8} \mathrm{O}_{7} \cdot \mathrm{H}_{2} \mathrm{O}\right.$, 99.5-102\%) was utilised as catalyst. All precursors were obtained from Sigma-Aldrich. Distilled water was used as the solvent. Aqueous stock solutions of network formers were prepared by dissolving the tetraethyl orthosilicate (TEOS, $\mathrm{C}_{8} \mathrm{H}_{20} \mathrm{O}_{4} \mathrm{Si}, 98 \%$ ) and the triethyl phosphate (TEP, $\mathrm{C}_{6} \mathrm{H}_{15} \mathrm{O}_{4} \mathrm{P}, \geq 99.8 \%$ ), both from Sigma-Aldrich, in the acidic solution of the selected catalyst. The preparation of each TEOS-TEP solution started with the sequential addition of TEOS and TEP to the catalyst solution under stirring for $30 \mathrm{~min}$ to obtain a clear sol. The concentrations of acid catalysts and water content are shown in Table 2. The sodium and calcium salts were separately dissolved in water. The Na-precursor solution was firstly added to the TEOS-TEP solution under stirring; $10 \mathrm{~min}$ after, the Ca-precursor solution was adjoined. The overall mixtures, reported in Table 2, were stirred for further $30 \mathrm{~min}$ as illustrated in Fig. 1. All the preparations were carried out at room temperature (RT) using a fixed stirring rate of $900 \mathrm{rpm}$.

A Buchi 210 Rotavapor evaporator with V-850 vacuum controller

Table 2

Concentrations of precursors and acid catalysts in the starting aqueous solutions for each composition.

\begin{tabular}{|c|c|c|c|c|c|c|c|}
\hline \multirow[t]{2}{*}{ № } & \multirow[t]{2}{*}{ Designation } & \multicolumn{3}{|c|}{$\begin{array}{l}\text { Precursors aqueous } \\
\text { solutions (mL) }\end{array}$} & \multicolumn{2}{|c|}{ Catalyst concentration } & \multirow{2}{*}{$\begin{array}{l}\text { Molar ratio } \\
\text { of } \mathrm{H}_{2} \mathrm{O} / \\
\text {-total } \\
\text { reactants }\end{array}$} \\
\hline & & TEOS + TEP & $\mathrm{Na}$ & $\mathrm{Ca}$ & $\mathrm{HNO}_{3}$ & $\mathrm{C}_{6} \mathrm{H}_{8} \mathrm{O}_{7} \cdot \mathrm{H}_{2} \mathrm{O}$ & \\
\hline 1 & S67C24-A & 20 & 15 & 35 & $1.3 \mathrm{M}$ & - & $\sim 22$ \\
\hline 2 & S59C32-A & 20 & 15 & 40 & $1.6 \mathrm{M}$ & - & $\sim 24$ \\
\hline 3 & S51C40-A & 20 & 15 & 55 & $1.35 \mathrm{M}$ & - & $\sim 28$ \\
\hline 4 & S49C45-A & 20 & 15 & 65 & $1.7 \mathrm{M}$ & - & $\sim 32$ \\
\hline 5 & S44C48-A & 20 & 15 & 60 & $1.5 \mathrm{M}$ & - & $\sim 30$ \\
\hline 6 & S67C24-N & 20 & 10 & 50 & - & $0.25 \mathrm{M}$ & $\sim 25$ \\
\hline 7 & S59C32-N & 20 & 10 & 55 & - & $0.25 \mathrm{M}$ & $\sim 27$ \\
\hline 8 & S51C40-N & 20 & 10 & 60 & - & $0.25 \mathrm{M}$ & $\sim 30$ \\
\hline 9 & S49C45- N & 20 & 10 & 70 & - & $0.26 \mathrm{M}$ & $\sim 31$ \\
\hline 10 & S44C48- N & 20 & 10 & 70 & - & $0.26 \mathrm{M}$ & $\sim 31$ \\
\hline
\end{tabular}




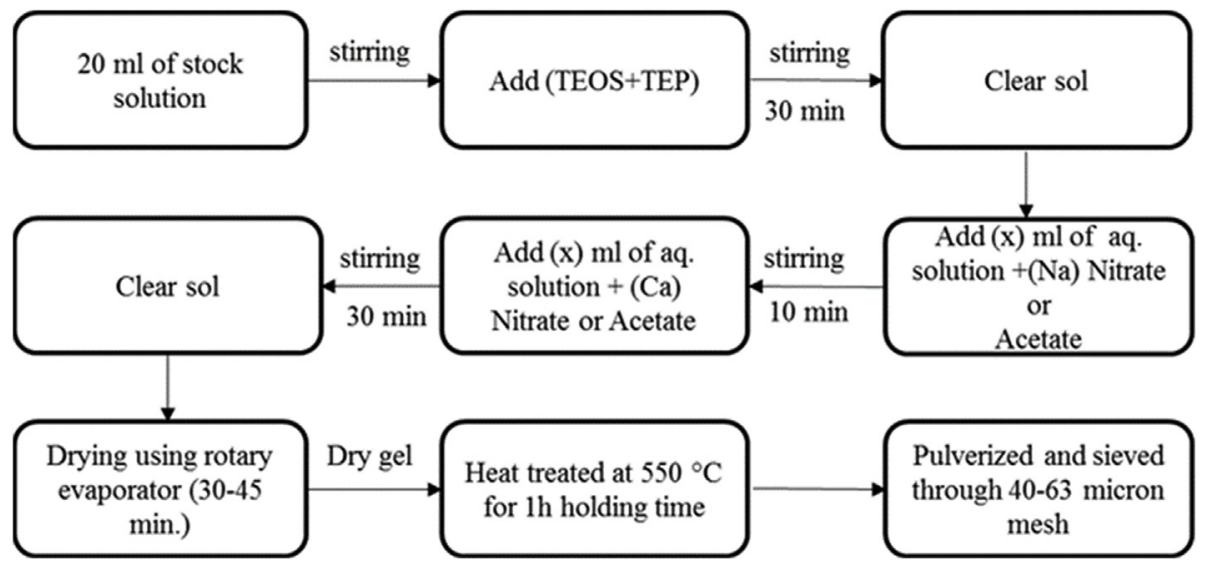

Fig. 1. General basic flow chart of the sol-gel glass synthesis process.

(50 mbar), a V-700 diaphragm vacuum pump (Buchi Labortechnik AG, Flawil, Switzerland), and a $500 \mathrm{~mL}$ flask rotating in a water bath at $55^{\circ} \mathrm{C}$ was used to dry the sols for $30-45 \mathrm{~min}$ [19-21]. This drying technique is 100 times faster than the most expedite standard drying and ageing methods for obtaining gel glass precursor [19].

The letters $\mathbf{A}$ (for acetate) and $\mathbf{N}$ (for nitrate) were added to the sample codes in Table 1 to identify the synthesis routes. The dried gels were thermally stabilised at $550^{\circ} \mathrm{C}$ in air for $1 \mathrm{~h}$. The heat treatment schedule included a heating rate of $1{ }^{\circ} \mathrm{C} \mathrm{min}-1$ up to $300{ }^{\circ} \mathrm{C}$, a plateau of $1 \mathrm{~h}$ at this temperature, a ramp of $10^{\circ} \mathrm{C} \mathrm{min}^{-1}$ up to $550^{\circ} \mathrm{C}$, or up to $800^{\circ} \mathrm{C}$, and holding for $1 \mathrm{~h}$ at the maximum temperature, followed by natural cooling to RT. The aim was to investigate the effect of calcination temperature on biocompatibility. The calcined glass powders were ground using a mortar and pestle, and sieved through 63 and $40 \mu \mathrm{m}$ meshes. For the glass powder heat treated at $550{ }^{\circ} \mathrm{C}$, the fraction below $40 \mu \mathrm{m}$ was used for the bio-mineralisation experiments in SBF according to a unified procedure disclosed elsewhere [22]. The results of bio-mineralisation assessment for the samples heat treated to $800{ }^{\circ} \mathrm{C}$ have been reported previously [23]. The SBF solution ( $1 \mathrm{~L})$ was prepared according to Kokubo's method [24], by dissolving in deionised (DI) water the proper amounts of the following reagents: $\mathrm{NaCl}$, $\mathrm{NaHCO}_{3}, \mathrm{KCl}, \mathrm{K}_{2} \mathrm{HPO}_{4} \cdot 3 \mathrm{H}_{2} \mathrm{O}, \mathrm{MgCl}_{2} \cdot 6 \mathrm{H}_{2} \mathrm{O}, 1 \mathrm{M} \mathrm{HCl}, \mathrm{CaCl}_{2} \cdot 2 \mathrm{H}_{2} \mathrm{O}$, $\mathrm{Na}_{2} \mathrm{SO}_{4}$ and Tris (hydroxymethyl)-aminomethane All the reagents (Sigma-Aldrich) and DI water were mixed in a polypropylene beaker at $37 \pm 1.0^{\circ} \mathrm{C}$.

\subsection{Bioactivity tests}

The in vitro bioactivity assessment in simulated body fluid (SBF) was performed by immersion of $75 \mathrm{mg}$ of glass powders in $50 \mathrm{~mL}$ of SBF solution at $37^{\circ} \mathrm{C}$, using sealed plastic flasks [22]. The flasks were immediately placed in an incubator at $37 \pm 0.5^{\circ} \mathrm{C}$ in an orbital shaker agitating at $120 \mathrm{rpm}$ for 4 different time periods: $4 \mathrm{~h}, 24 \mathrm{~h}, 1$ week, and 3 weeks. The unified protocol proposed elsewhere [22] establishes that an exposed standard sample area of $0.5 \mathrm{~cm}^{2} / \mathrm{mL}$ of SBF solution, irrespective of its geometry (bulk samples, powders, thin films, scaffolds, etc.) should be used. The aim is to facilitate the comparison of the findings from different laboratories [22]. At each time point, the powder was collected by ultra-centrifuging (Beckman model LB-70 M) the mixture under vacuum at $10,000 \mathrm{rpm}$ for $30 \mathrm{~min}$. The $\mathrm{pH}$ of the supernatant solutions was measured directly, and the separated powders were successively washed with deionised water and acetone, and then dried overnight at $37^{\circ} \mathrm{C}$. The experiments were performed in triplicate in order to ensure the accuracy of results. The apatite-forming ability of the glass powders was followed by XRD, FTIR, EDS and $\mathrm{pH}$ measurements.

\subsection{Glass characterisation}

The SSA of the powders was measured by the Brunauer-Emmett-Teller (BET) method using a Gemini M-2380 instrument (Micrometrics) with $\mathrm{N}_{2}$ as the adsorbate. The samples were previously degassed at $200{ }^{\circ} \mathrm{C}$. The skeletal density of the powders was measured by helium pycnometry after overnight drying at $60^{\circ} \mathrm{C}$.

Triplicate particle size distribution measurements were performed using a dynamic laser scattering (DLS) analyser (Coulter LS Particle Size Analyzer; Beckman Coulter). $\sim 0.3 \mathrm{~g}$ of glass powder was dispersed in $50 \mathrm{~mL}$ tap water, kept in ultrasound for $5 \mathrm{~min}$ to eliminate any agglomerates, and fed dropwise to the instrument. The DLS was operating in Fraunhofer optical model with triplicate runs, the run length being $61 \mathrm{~s}$. The particle size distribution (PSD) is presented as differential volume in volume $\%$.

$\mathrm{X}$-ray diffraction (XRD) analysis was performed using a PANalytical XPERT-PRO Diffractometer system, utilizing $\mathrm{Cu} \mathrm{Ka}$ radiation (Ko $=1.54059 \AA$ ) with $2 \theta$ varying from 6 to $70^{\circ}$ with step size of 0.013 and step time 200 (s). Powder samples before and after immersion in simulated body fluid (SBF) were analysed and the resulting diffraction patterns were compared with the Joint Committee on Powder Diffraction Standards (JCPDS).

Solid state ${ }^{29}$ Si MAS-NMR (magic-angle spinning nuclear magnetic resonance) was used to investigate the extents of silica polymerisation of the stabilised glasses. The spectra were recorded on an ASX 400 spectrometer (Brucker) operating at $79.52 \mathrm{MHz}(9.4 \mathrm{~T})$, using a $7 \mathrm{~mm}$ probe at a spinning rate of $5 \mathrm{kHz}$. The pulse length was $2 \mu \mathrm{s}$ with $60 \mathrm{~s}$ delay time. Kaolinite was used as a chemical shift reference. Due to the high noise signal acquired for low silica glasses, only the high silica glasses (S67C24-A/N) spectra were deconvoluted using dimFit software.

Infrared transmittance spectra of the glasses, before and after immersion in SBF, were obtained using a Fourier Transform Infrared Spectrometer (FTIR, Tensor 27, Brucker) in the range of $350-4000 \mathrm{~cm}^{-1}$, with 128 Scans and $4 \mathrm{~cm}^{-1}$ resolution. The pellets were prepared by pressing a mixture of glass powder and $\mathrm{KBr}$ with a weight ratio of 1:150.

The compositional surface modifications of the glasses after immersion in SBF were assessed by energy dispersive spectroscopy (EDS, Bruker Nano GmbH) on a scanning electron microscope (SEM, S-4100, Hitachi). The SEM samples were prepared by depositing the powder particles directly onto adhesive carbon tapes and further coating using carbon.

\subsection{Biocompatibility tests}

The in vitro cytotoxicity tests were performed using two cell lines, MG63 (ATCC CRL-1427, Human osteosarcoma) and C13589 (ATCC 
CRL-2704, Human B lymphoblasts), following the ISO 10993-5 guidelines of the International Organisation for Standardisation (ISO 2009) [25]. Only some N-glasses (S67C24N, S59C32N and S51C40N) were selected because of their lower contents of nitrate residues and calcite, as will be discussed later. The samples heat treated at $550{ }^{\circ} \mathrm{C}$ and $800{ }^{\circ} \mathrm{C}$ were sterilised by UV-radiation prior to testing them in cell cultures through the MTT assay, measuring the metabolic activity of living cells via mitochondrial dehydrogenase activity through its key component (3-[4,5-dimethylthiazol-2-yl]-2,5- diphenyl tetrazolium bromide).

MG63 cells were maintained in Dulbecco's Modified Eagle Medium (DMEM, Sigma Aldrich) supplemented with $10 \%(\mathrm{v} / \mathrm{v})$ of foetal bovine serum (FBS, Sigma Aldrich), penicillin $\left(100 \mathrm{U} \mathrm{mL}^{-1}\right.$ culture medium, Sigma Aldrich), streptomycin $\left(100 \mu \mathrm{g} \mathrm{mL}^{-1}\right.$ culture medium, Sigma Aldrich), L-glutamine (5\%, Sigma Aldrich) and sodium pyruvate (5\%, Sigma Aldrich). C13589 cells were maintained in Roswell Park Memorial Institute 1640 (RPMI, Sigma Aldrich) supplemented with $10 \%(\mathrm{v} / \mathrm{v})$ of foetal bovine serum (FBS, Sigma Aldrich), penicillin (100 $\mathrm{U} \mathrm{mL}^{-1}$ culture medium, Sigma Aldrich), streptomycin $(100 \mu \mathrm{g} \mathrm{mL}$ culture medium, Sigma Aldrich), L-glutamine (5\%, Sigma Aldrich). All cell lines were grown in a humidified incubator at $37^{\circ} \mathrm{C}$, with $5 \% \mathrm{CO}_{2}$ and $95 \%$ relative humidity.

The viability of cells exposed to different concentrations [0.00 (CTR), $0.05,0.15,0.30$ and $0.75 \mathrm{mg} \mathrm{mL}^{-1}$ ] of each glass powder dispersed in the cell culture media was determined by seeding the cell lines into 24 well plates at $1 * 10^{5}$ cells per well. The in vitro cytotoxicity was evaluated via MTT assay, according to the manufacturer's instructions (Sigma-Aldrich). The absorbance was spectrophotometrically measured at a wavelength of $570 \mathrm{~nm}$, and the background absorbance measured at $690 \mathrm{~nm}$ was subtracted. The percentage of cell viability was expressed as the relative growth rate (RGR) by the equation:

$R G R(\%)=\frac{D_{\text {sample }}}{D_{\mathrm{CTR}}} \times 100$

where $D_{\text {sample }}$ and $D_{\text {CTR }}$ were the absorbance of the sample and of the negative control $\left(0.00 \mathrm{mg} \mathrm{mL}^{-1}\right)$, respectively. Each experiment was triplicated (Student's t-test, $P<0.05$ ).

\section{Results}

\subsection{XRD for the stabilised glasses}

The XRD patterns of the samples thermally stabilised at $550{ }^{\circ} \mathrm{C}$ shown in Fig. 2 reveal a broad band within the 2Theta range of $20-30^{\circ}$, due to the predominant presence of an amorphous phase. These results are in good agreement with those reported elsewhere [26,27]. The A - glasses Fig. 2(a) exhibit crystalline HAp [PDF card 01-080-3956] for all calcium contents, along with the formation of small amounts of a silica phase [coesite, PDF card \#04-015-7166] in some cases. The XRD and FTIR analyses of the samples heat treated to $800{ }^{\circ} \mathrm{C}$ have been reported previously [23]. The increase of heat treatment temperature from $550{ }^{\circ} \mathrm{C}$ to $800^{\circ} \mathrm{C}$ tend to increase the devitrification trend, and decrease the specific surface area and the pore volume.

\subsection{MAS-NMR analysis for the stabilised glasses}

The ${ }^{29}$ Si MAS NMR spectra of $\mathrm{A}-$ glasses and $\mathrm{N}-$ glasses are shown in Fig. 3. Only the compositions containing 24, 32, and $40 \mathrm{Ca}$ were chosen for NMR analysis for two reasons: (i) higher Ca contents were found to readily induce the precipitation of the undesired calcite phase upon immersion in SBF; (ii) the acquired signal became gradually noisier with decreasing silica contents. The structural $Q^{n}$ speciation (where $n$ denotes the number of bridging oxygens (BO) and may acquire the values of $1,2,3$ or 4 ) can be inferred from NMR spectra reported in Table 3 for the S67C24 composition. The A-glasses are generally less polymerised and exhibit lower values of network connectivity $(\mathrm{Nc}=3)$ than $\mathrm{N}-$ glasses $(\mathrm{Nc}=3.3)$.

\subsection{FTIR spectra for the stabilised glasses}

The FTIR spectra of the thermally stabilised at $550{ }^{\circ} \mathrm{C}$ for $\mathrm{A}$ - glasses and $\mathrm{N}$ - glasses are displayed in Fig. 4(a), and Fig. 4(b), respectively. All the spectra are dominated by a broad band between 800 and $1300 \mathrm{~cm}^{-1}$, assigned to asymmetric stretching for $\mathrm{Si}-\mathrm{O}-\mathrm{Si}$ (s), which becomes gradually shallower as Si content decreases [28]. Both routes provide glasses with almost similar features. The broad band centred at $\sim 1090-1100 \mathrm{~cm}^{-1}$ is attributed to the $\mathrm{Si}-\mathrm{O}-\mathrm{Si}$ (s) transverse optical stretching mode $\left(\mathrm{TO}_{1}\right)$. This peak is shifted to a lower wavenumber $\sim 1040 \mathrm{~cm}^{-1}$ by increasing the Ca content (S51C40, S49C45, and S44C48) due to higher contributions of $Q^{3}$ species [29]. The relatively small band at $1640 \mathrm{~cm}^{-1}$ in all glasses is due to the presence of $\mathrm{H}_{2} \mathrm{O}$ [30]. The band at $1460 \mathrm{~cm}^{-1}$ in $\mathrm{N}-$ glasses, and its two separate peaks at 1490 and $1420 \mathrm{~cm}^{-1}$, can be assigned to amorphous calcite [31,32]. The sharp peak at around $1385 \mathrm{~cm}^{-1}$, attributed to the $\mathrm{NO}_{3}{ }^{-}$group [33], appears with a higher intensity in the case of A-glasses.

The shoulder positioned at $\sim 1220 \mathrm{~cm}^{-1}$ in Fig. 4(a-b) may represent the $\mathrm{Si}-\mathrm{O}-\mathrm{Si}(\mathrm{s}),\left(\mathrm{TO}_{2}\right)$ stretching mode [34], or be also assigned to $\mathrm{P}-\mathrm{O}$ stretch vibration [35]. The band at $930 \mathrm{~cm}^{-1}$ intensified with increasing $\mathrm{Ca}$ contents, and can be attributed to the $\mathrm{Si}-\mathrm{O}-\mathrm{Si}$ stretching vibration mode of non-bridging oxygens (NBO) [15]. The very small
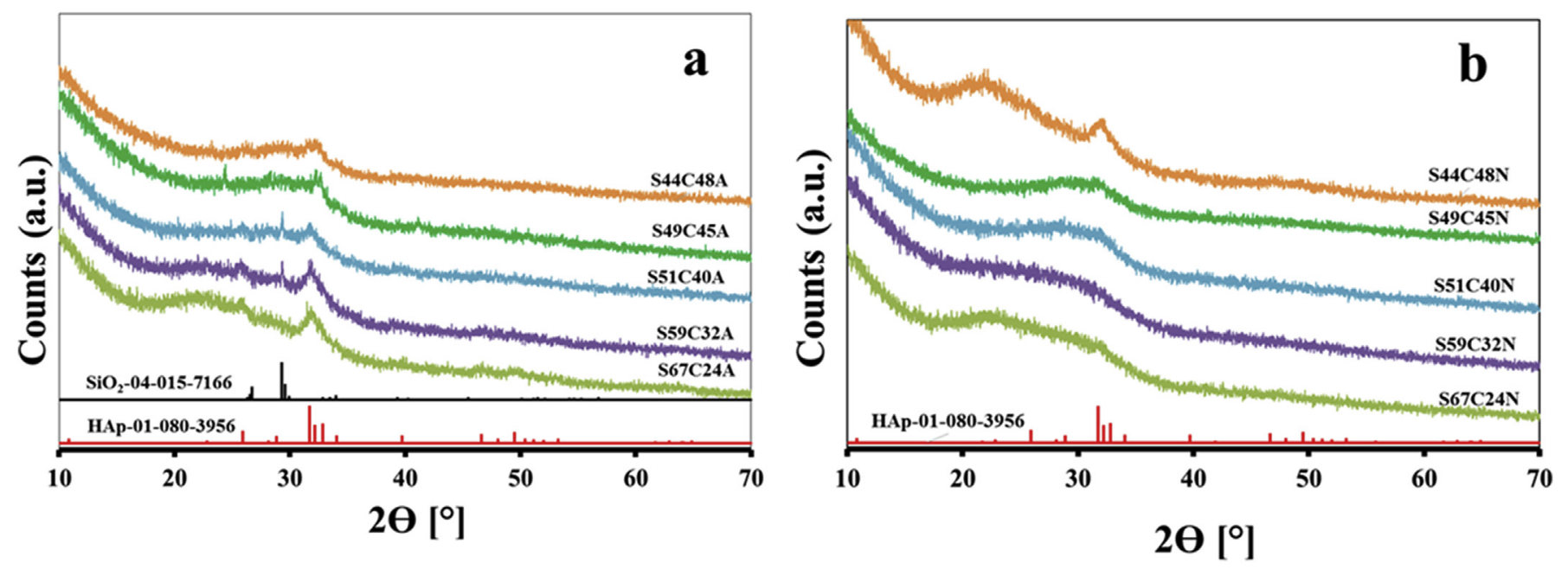

Fig. 2. XRD patterns of the glasses synthesised through different routes and thermally stabilised at $550{ }^{\circ} \mathrm{C}$ : (a) A-glasses; (b) $\mathrm{N}-$ glasses. 

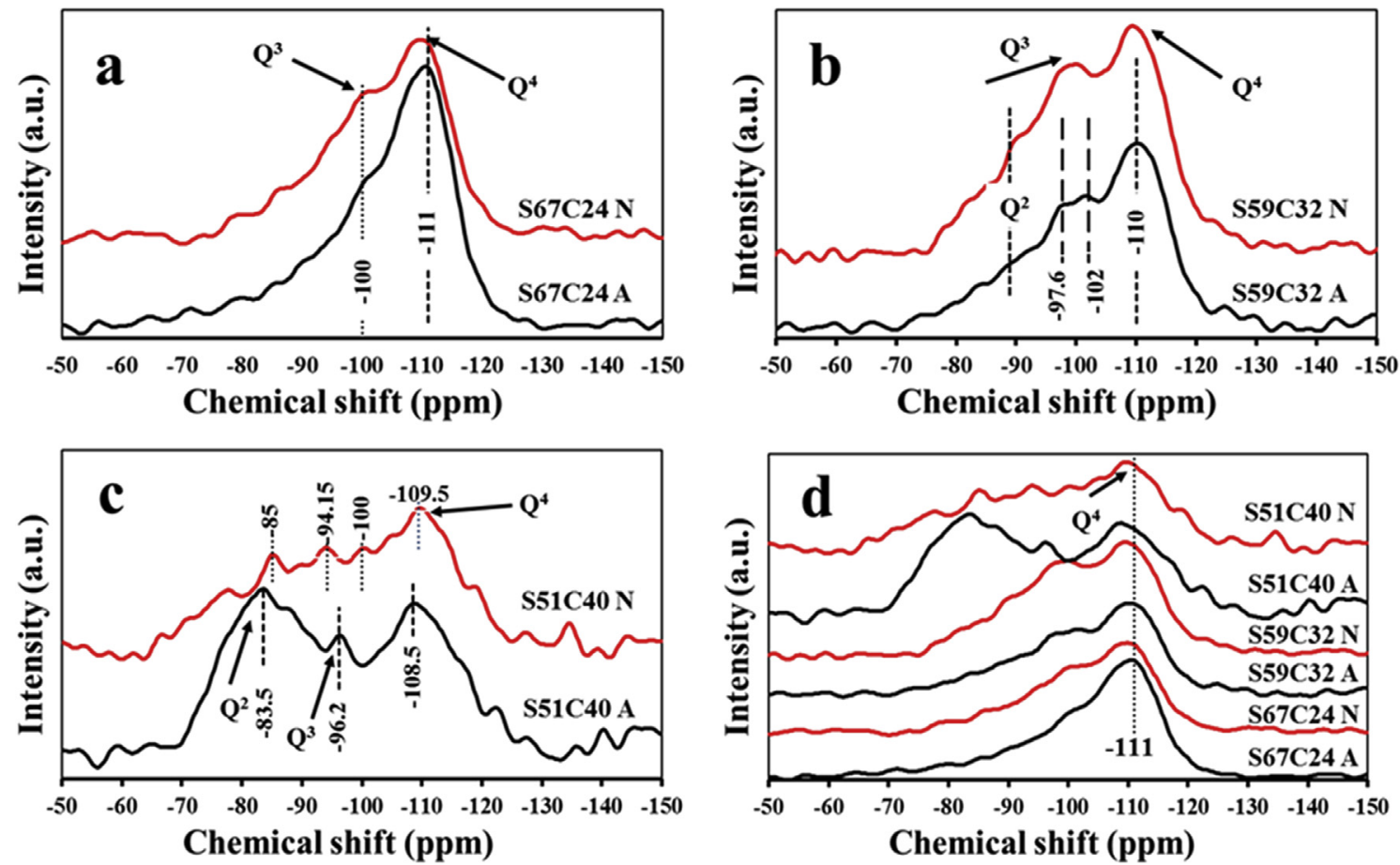

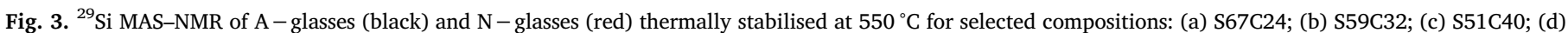

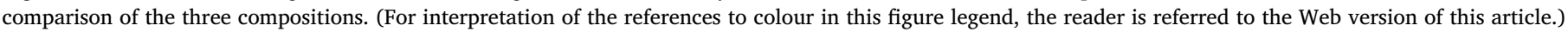

Table 3

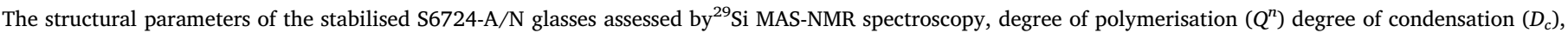
and network connectivity $\left(N_{c}\right)$.

\begin{tabular}{|c|c|c|c|c|c|c|c|c|}
\hline \multirow[t]{3}{*}{ Sample } & \multicolumn{6}{|l|}{$Q^{n}$} & \multirow[t]{3}{*}{$D_{c}(\%)$} & \multirow{3}{*}{$\frac{N_{c}}{\text { from }{ }^{29} \text { Si MAS NMR }}$} \\
\hline & \multicolumn{2}{|l|}{$Q^{2}$} & \multicolumn{2}{|l|}{$Q^{3}$} & \multicolumn{2}{|l|}{$Q^{4}$} & & \\
\hline & Peak position (ppm) & Integral \% & Peak position (ppm) & Integral $\%$ & Peak position (ppm) & Integral \% & & \\
\hline S67C24-A & -93.08 & 27.7 & -105.2 & 45.8 & -111.1 & 26.5 & 74.7 & 3.0 \\
\hline S67C24-N & -89.6 & 8.8 & -100.01 & 53.9 & -110.2 & 37.3 & 82.1 & 3.3 \\
\hline
\end{tabular}

peaks at around $880 \mathrm{~cm}^{-1}$ [34] along with the band at around $1460 \mathrm{~cm}^{-1}$ [36], are assigned to bending $\mathrm{CO}_{3}(\mathrm{~b})$, and stretching $\mathrm{CO}_{3}(\mathrm{~s})$ respectively. The two tiny peaks around 825 and $800 \mathrm{~cm}^{-1}$ are related to symmetric stretching of $\mathrm{Si-O}-\mathrm{Si}$ (s) [37]. The twin sharp peaks at 603 and $570 \mathrm{~cm}^{-1}$ correspond to the $\mathrm{P}-\mathrm{O}$ bending vibration of $\mathrm{PO}_{4}^{-3}$ (b) tetrahedra. The presence of these two peaks indicates the formation of HAp [35,38]. The low wavenumber band at $\sim 490 \mathrm{~cm}^{-1}$ for high calcium content glasses can be assigned to the symmetric vibration of $\mathrm{Si}-\mathrm{O}-\mathrm{Si}$ [26]. In the low calcium content glasses, this band shifted to about $\sim 470 \mathrm{~cm}^{-1}$, and can be assigned to the bending vibrating mode
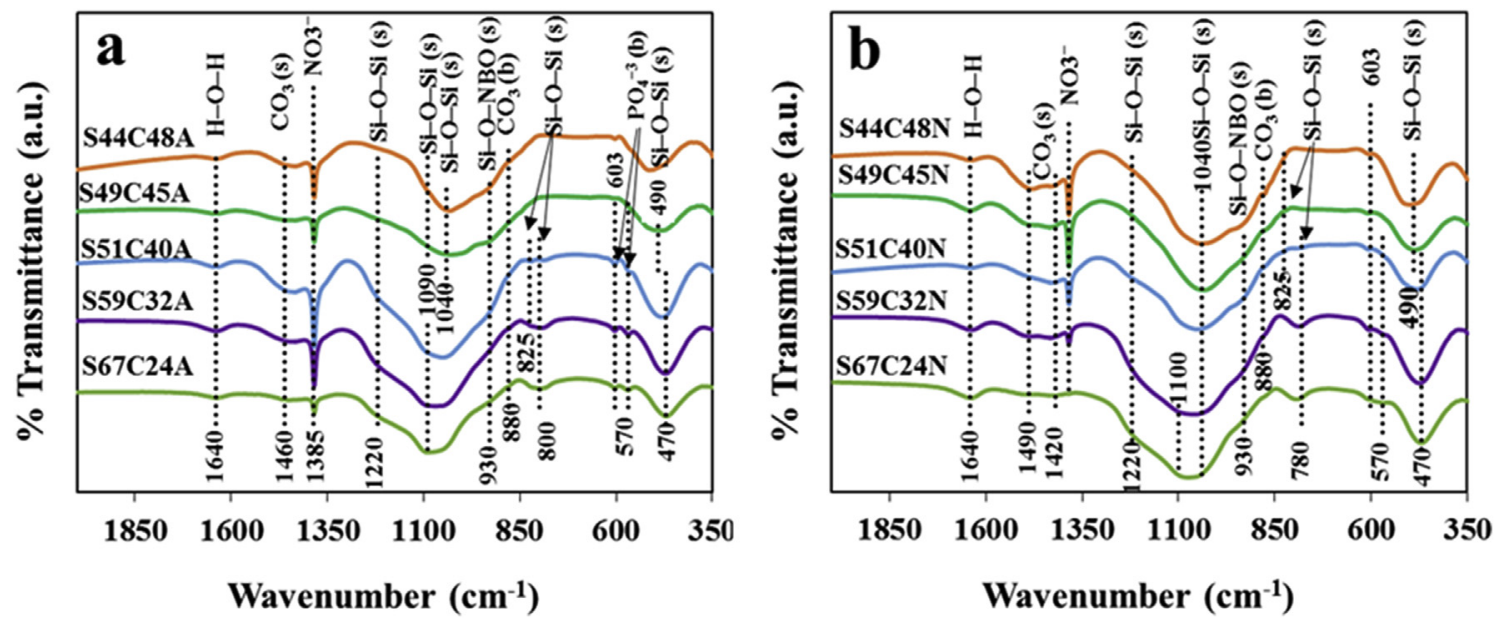

Fig. 4. FTIR spectra of all glass compositions thermally stabilised at $550{ }^{\circ} \mathrm{C}$ : (a) A-glasses; (b) $\mathrm{N}-$ glasses. 
Table 4

Density, particle size and SSA for the glasses heat-treated for $1 \mathrm{~h}$ at $550{ }^{\circ} \mathrm{C}$.

\begin{tabular}{llll}
\hline Designation & Density $\pm \mathrm{SD}$ & Particle size $\pm \mathrm{SD}$ & \multirow{2}{*}{ SSA $\left(\mathrm{m}^{2} \mathrm{~g}^{-1}\right)$} \\
\cline { 2 - 3 } & $\left(\mathrm{g} \mathrm{cm}^{-3}\right)$ & $\mathrm{d} 50(\mu \mathrm{m})$ & \\
\hline S67C24-A & $2.25 \pm 0.04$ & $19.2 \pm 0.04$ & 35.0 \\
S67C24-N & $2.31 \pm 0.06$ & $23.3 \pm 0.11$ & 99.5 \\
S59C32-A & $2.34 \pm 0.08$ & $23.6 \pm 0.16$ & 53.5 \\
S59C32-N & $2.37 \pm 0.05$ & $23.7 \pm 0.11$ & 72.5 \\
S51C40-A & $2.24 \pm 0.08$ & $15.1 \pm 0.51$ & 28.4 \\
S51C40-N & $2.30 \pm 0.04$ & $16.6 \pm 0.06$ & 32.4 \\
S49C45-A & $2.42 \pm 0.02$ & $24.5 \pm 0.11$ & 51.1 \\
S49C45-N & $2.49 \pm 0.04$ & $25.6 \pm 0.23$ & 56.8 \\
S44C48-A & $2.56 \pm 0.03$ & $15.3 \pm 0.40$ & 53.1 \\
S44C48-N & $2.61 \pm 0.04$ & $17.8 \pm 0.31$ & 58.7 \\
\hline
\end{tabular}

of P-O-P bonds of the HAp phosphate groups [39].

\subsection{Density, particle size and SSA}

Table 4 shows the density, $d_{50}$ and SSA for the ten prepared glasses. The A-glasses are noticeably less dense $\left(2.24-2.56 \mathrm{~g} \mathrm{~cm}^{-3}\right)$ than $\mathrm{N}$ - glasses $\left(2.30-2.61 \mathrm{~g} \mathrm{~cm}^{-3}\right)$. The average particle sizes (after sieving through a $40 \mu \mathrm{m}$ mesh) were almost similar, varying within the ranges of 15.1-24.5 $\mu \mathrm{m}$, and $16.6-25.60 \mu \mathrm{m}$, for A-glasses and $\mathrm{N}$-glasses, respectively. The smaller particle sizes were measured for the lower $\mathrm{Ca}$ contents, S51C40 and S44C48, irrespective of the synthesis route. The A-glasses exhibited SSA values in the range of $28.4-53.5 \mathrm{~m}^{2} \mathrm{~g}^{-1}$, lower than those of $\mathrm{N}$-glasses that varied within the range of $32.4-99.5 \mathrm{~m}^{2} \mathrm{~g}^{-1}$.

\subsection{Bioactivity assessment}

\subsubsection{XRD after immersion in simulated body fluid (SBF)}

Fig. 5(a-e) display the XRD patterns of $\mathrm{A}-$ glasses and $\mathrm{N}$-glasses after immersion in SBF for different time periods up to 3 weeks. The presence of crystalline (A - glasses) and semi crystalline or amorphous HAp ( $\mathrm{N}-$ glasses) could be identified even before immersion $(0 \mathrm{~h})$. This finding is in a good agreement with the results reported elsewhere [40]. The early formation of HAp during Sol-Gel synthesis can be considered a good attribute, acting as seeding for the new HAp formation upon SBF immersion.

\subsubsection{FTIR spectra after immersion in $S B F$}

Fig. 6 shows the evolution of FTIR peaks/bands of glasses over different immersion time periods in SBF. The wide band centred at $\sim 1450 \mathrm{~cm}^{-1}$ is assigned to the $\mathrm{C}-\mathrm{O}$ group. The evolution of the peak at $870-880 \mathrm{~cm}^{-1}$ confirms the formation of type-A carbonated hydroxyapatite (CHAp) resulting from the $\mathrm{CO}_{3}$ substituting for $\mathrm{OH}$ into apatite lattice [41]. The band centred at $1450 \mathrm{~cm}^{-1}$ and the peak at $880 \mathrm{~cm}^{-1}$ also support this hypothesis.

Two sharp phosphate peaks characteristic of HAp at around 560 and $600 \mathrm{~cm}^{-1}$ are clearly present after just $4 \mathrm{~h}$ of immersion for both A - glasses and $\mathrm{N}-$ glasses. A peak observed at $960 \mathrm{~cm}^{-1}$ could be also assigned to $\mathrm{P}-\mathrm{O}$ symmetric stretching in the CHAp layer formed onto the surface of the powders [42].

\subsubsection{Evolution of $p H$ (supernatant SBF solutions) and of glass surface compositions}

The $\mathrm{pH}$ variations along the immersion time in SBF for the 67SC24, 59SC32 and 51SC40 glasses synthesised by both routes exhibit almost identical trends as shown in Fig. 7. The same can be stated concerning the qualitative surface $\mathrm{Ca}$ and $\mathrm{P}$ atomic concentrations of $\mathrm{A}$-glasses and $\mathrm{N}$-glasses immersed in SBF for different time periods estimated by EDS (Fig. 8), confirming the bioactivity results.

\subsection{Biocompatibility tests}

The results of in vitro biocompatibility detailed in section 2.3 are displayed in Fig. 9(a-f), revealing highest degree of cytocompatibility of MG63 cells towards S67C24 N glass Fig. 9(a,d). Cell viability of at least $70 \%$ over all three tested time periods was found for concentration levels of up to $0.30 \mathrm{mg} \mathrm{mL}^{-1}$ and especially for the samples thermally stabilised at $800^{\circ} \mathrm{C}$ Fig. 9(d), become cytotoxic upon further incremental concentrations. Similar scenarios concerning the effects of thermal stabilisation temperature can also be observed for the other calcium-richer compositions tested Fig. 9(b-c), and Fig. 9(e-f).

The responses of lymphoblast C13895 Fig. $9(\mathrm{~g}-\mathrm{l})$ to the tested glasses suggest that these cells are sensitive to the extent of ionic leaching, with the higher degrees of cytotoxicity being registered for the samples thermally stabilised at $550^{\circ} \mathrm{C}$ Fig. $9(\mathrm{~h}-\mathrm{i})$. This hypothesis is also supported by the lower degree of cytotoxicity of less soluble S67C24 N sample Fig. $9(\mathrm{~g})$ in comparison to the other glasses with increasing Ca contents. These results are in a good agreement with the results obtained by Catauro et al. [17]. The enhanced biocompatibility of the Si-richer composition is not surprising, as silica is known to play here a key role in biocompatibility of bioactive glasses [43,44].

\section{Discussion}

\subsection{Synthesis route, nominal composition stabilisation temperature}

\subsubsection{XRD and MAS-NMR analyses}

The higher crystallisation trend observed for A-glasses is probably due to the faster Sol-Gel transition induced by the higher $\mathrm{pH}$ values of the starting sols, which may favour some segregation of the precursors. Oppositely, the slower hydration and condensation reactions going on in the more acidic sols of $\mathrm{N}$-glasses will enable a more homogeneous integration of all the components in the amorphous glassy structure $[45,46]$. This is confirmed for all compositions except for the one with the highest Ca content (S44C48N), which also shows some traces of hydroxyapatite (HAp) [PDF card \#01-080-3956] Fig. 2(b). This interpretation is consistent with (i) the higher polymerisation degrees and network connectivity values observed for $\mathrm{N}$-glasses in comparison to A - glasses; (ii) a decreasing intensity of the $Q^{4}$ band upon increasing Ca content at the expenses of silica (S59C32) is seen in Fig. 3(b). This depolymerisation trend becomes even more obvious upon further increasing the Ca content (S51C40) as shown in Fig. 3(c). This gradual deviation of $Q^{4}$ towards lower chemical shifts with decreasing Si contents from 67 to 51 is also accompanied by: (i) the appearance a band at -100 ppm corresponding to $Q^{3}$; (ii) the broadening of this band and its apparent deviation to lower negative chemical shifts towards the onset of $Q^{2}$ species between -97 to $-85 \mathrm{ppm}$, Fig. 3(c). This depolymerisation trend with increasing Ca contents leading to significant populations of $Q^{2}$ species is clear. However, the accurate identification and quantification of these species is difficult because the spectra become gradually noisier. The slightly lower degrees of polymerisation of $\mathrm{A}$ - glasses in comparison to $\mathrm{N}$-glasses of the same nominal compositions enable concluding that microstructure and network connectivity of the glasses can be partially manipulated by just changing the metal salt precursor. These results are in a good agreement with results published earlier by the authors [47].

\subsection{FTIR analysis}

The sharp peak observed at $1385 \mathrm{~cm}^{-1}$ in Fig. 4 can be attributed to the $\mathrm{NO}_{3}{ }^{-}$group [33]. Its intensity is higher in the case of $\mathrm{A}-$ glasses. These results are consistent with the fuel role of citric acid towards nitrates [8], inducing self-propagation combustion reactions, especially for proper molar ratios of metal salts/citric acid [48]. Therefore, higher amounts of nitrates will be eliminated in the case of as prepared $\mathrm{N}$-glasses in comparison to A-glasses. Further, acetate precursors are 


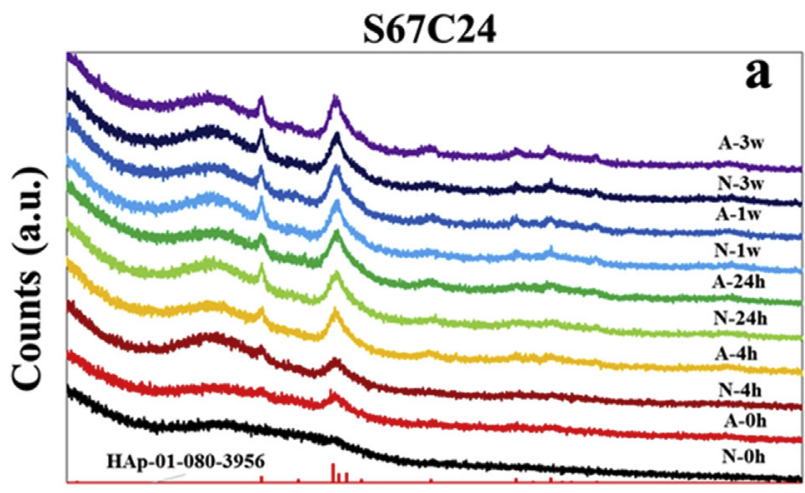

$\mathrm{S} 51 \mathrm{C} 40$

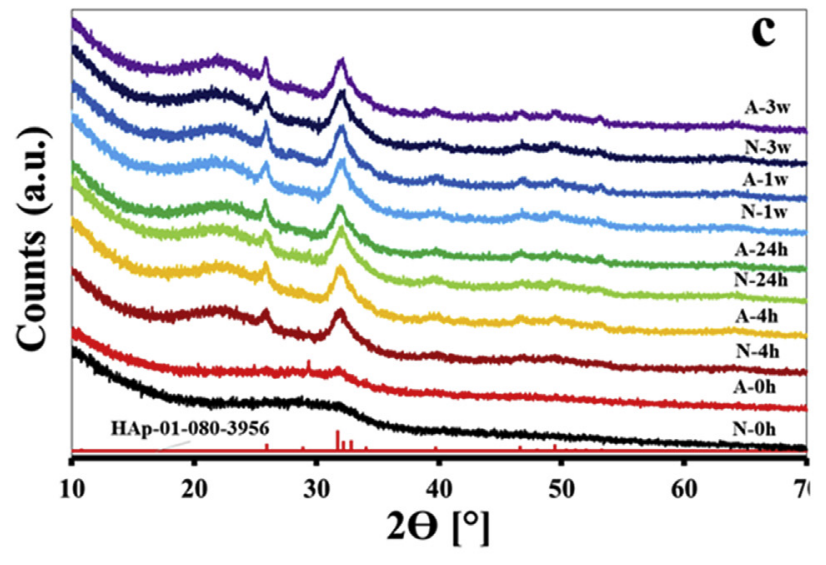

$\mathbf{S 5 9 C 3 2}$

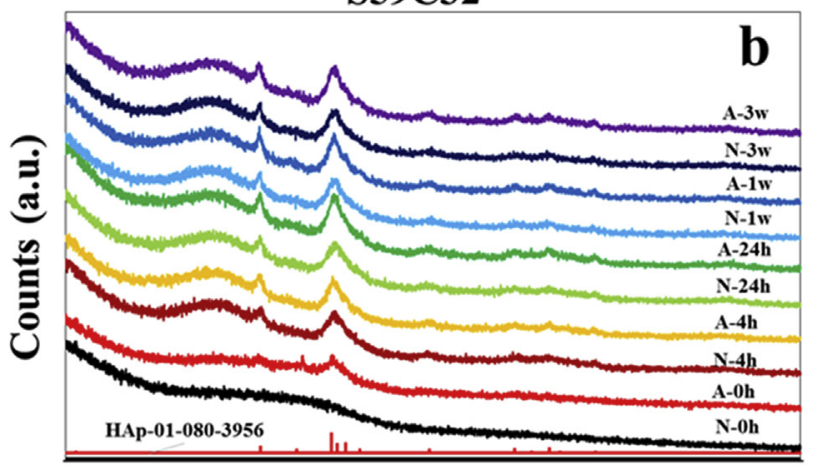

$\mathrm{S} 49 \mathrm{C} 45$

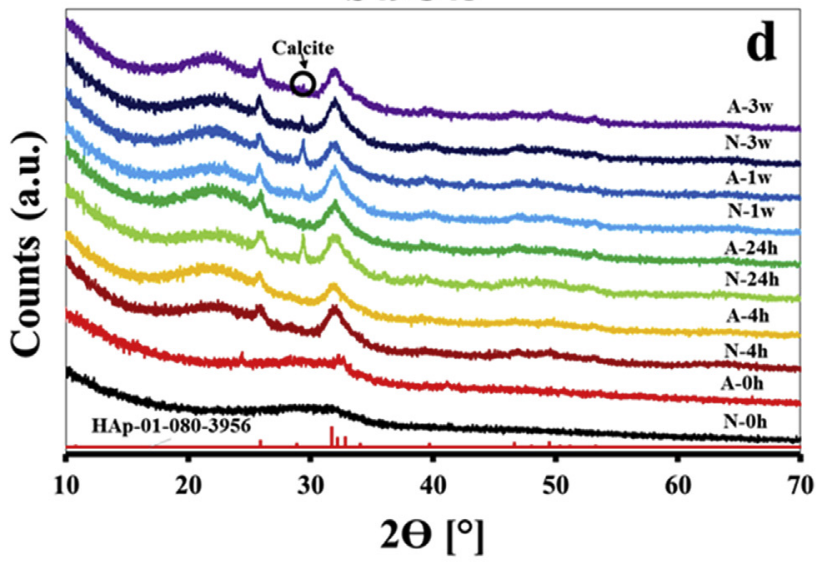

S44C48

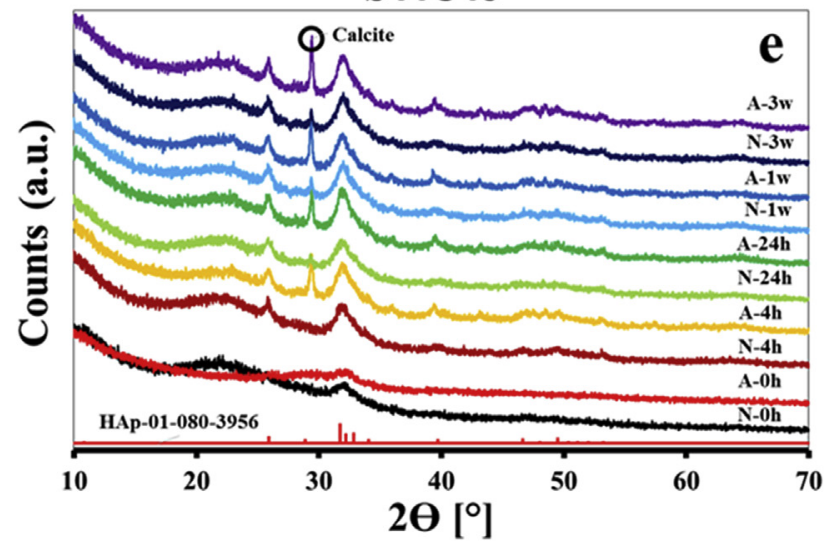

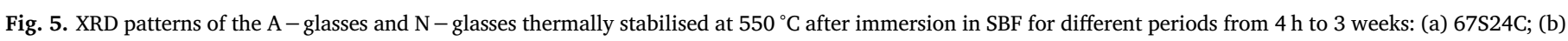
59S32C; (c) 51S40C; (d) 49S45C; (e) 44S48C.

highly basic salts, being often used as buffers [49]. To reduce the $\mathrm{pH}$ of acetate salt solutions a high amount of nitric acid has to be added, which serves two functions: (i) as catalyst; (ii) $\mathrm{pH}$ reducer of the sol to prevent fast gelation, which may occur immediately after adding one or both acetate metal salts.

\subsubsection{Density, particle size and SSA}

The results presented in Table 4 enable us to conclude that $\mathrm{N}$-glasses tend to exhibit higher skeletal densities, slightly coarser particles, and higher SSA. This last feature is likely to favour the in vitro bio-mineralisation rate of $\mathrm{N}$-glasses in comparison to A-glasses [50]. The higher skeletal densities of $\mathrm{N}$-glasses are consistent with the more extensive polymerisation, which in turn is likely to favour the grounding resistance, justifying the formation slightly coarser particles. On the other hand, the smaller values of SSA of the A-glasses can be attributed to a faster jellification process [51].

\subsection{Bioactivity assessment}

\subsubsection{XRD and FTIR analyses of samples immersed in $S B F$}

The crystalline $\mathrm{SiO}_{2}$ phase (coesite, PDF card \#04-015-7166) identified in some A-glasses in Fig. 2(a) has apparently disappeared just after $4 \mathrm{~h}$ of immersion in SBF. This apparent disappearance can only be attributed to: (i) its dissolution in the SBF solution; (ii) a masking effect caused by the deposition of a HAp (PDF \# 01-080-3956) surface layer [52]. The intensity of XRD peaks of HAp gradually increases between $4 \mathrm{~h}$ and 3 weeks as shown in Fig. 5. These observations are in agreement with the bio-mineralisation mechanism proposed by Hench et al. [53]. The HAp phase in A - glasses noticed for shorter immersion periods could be attributed to the seeding role of the 

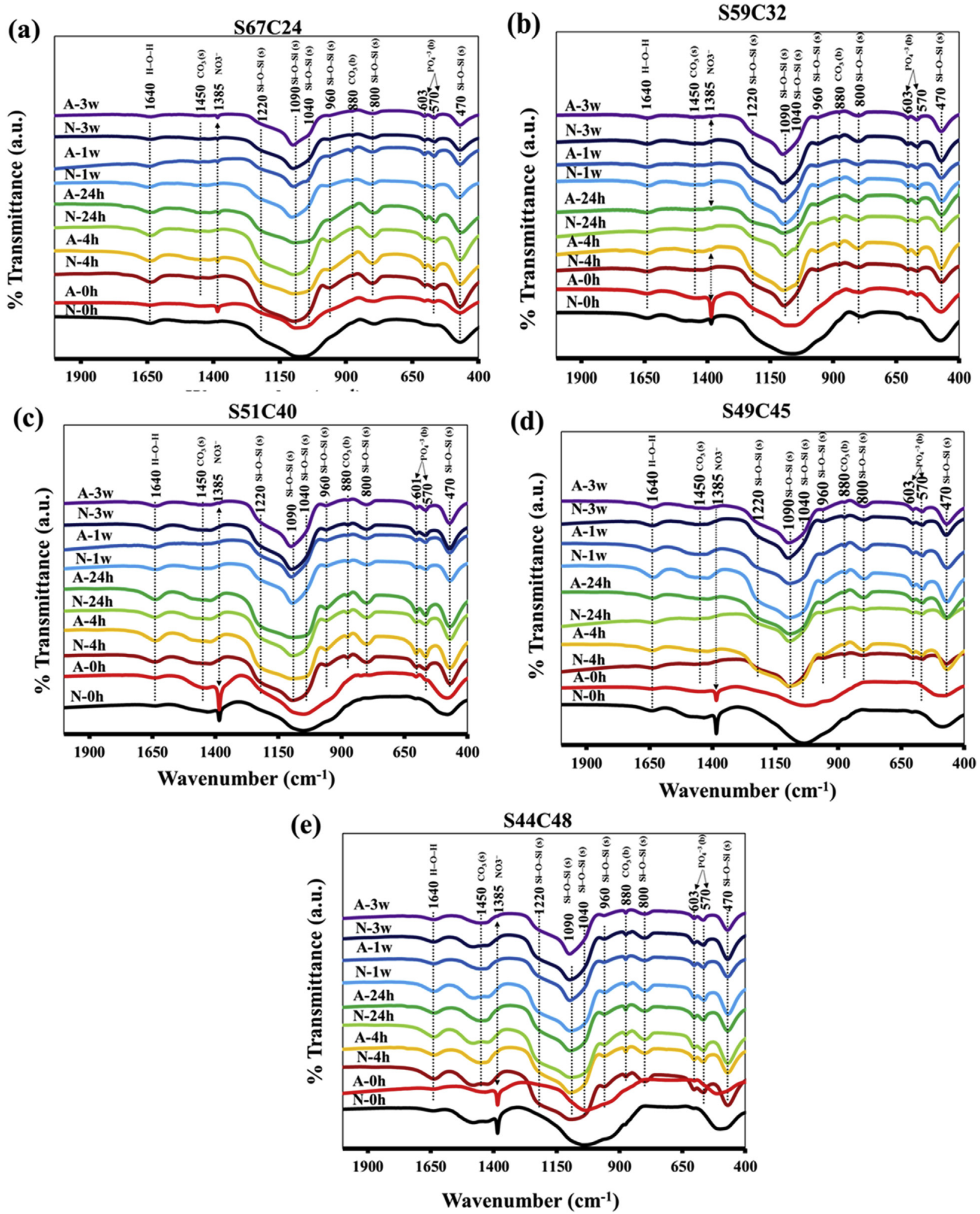

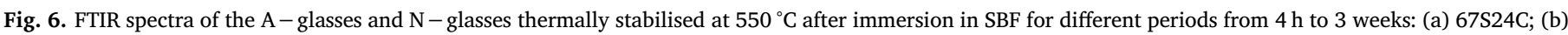
59S32C; (c) 51S40C; (d) 49S45C; (e) 44S48C.

previously formed HAp before SBF immersion as discussed in Fig. 2(a). Although initially revealing less crystalline HAp Fig. 2(b), N-glasses have undergone a more extensive bio-mineralisation process as deduced from the intensification of HAp XRD peaks after 3 weeks of immersion. The XRD peaks of HAp becoming better defined and sharper as immersing time increases. Although the surface modifications are less evident from the FTIR spectra (Fig. 4), N-glasses show sharper and better defined peaks supporting its enhanced bioactivity in comparison to A-glasses. These observations support the hypothesis admitted above (section 4.4.1) that higher SSA of $\mathrm{N}$-glasses could favour the in vitro bio-mineralisation rate.

The calcite phase $\left(\mathrm{CaCO}_{3}, \mathrm{PDF} \# 00-005-0586\right)$, identified at the 


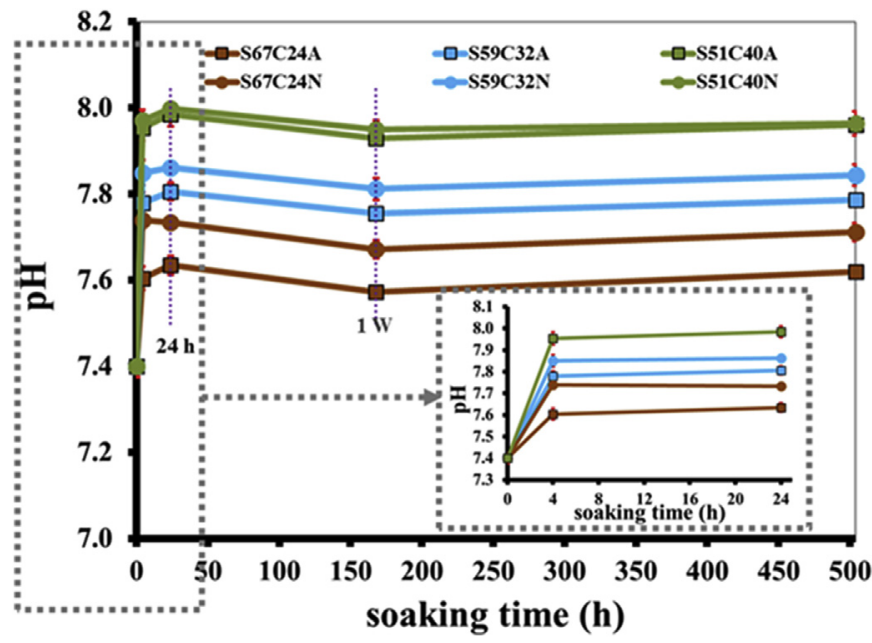

Fig. 7. $\mathrm{pH}$ values measured in the supernatant SBF liquids remaining after the indicated immersion time points for selected compositions (S67C24, S59C32, S51C40) of A-glasses and $\mathrm{N}$-glasses thermally stabilised at $550{ }^{\circ} \mathrm{C}$.

early stages of SBF immersion in the S44C48 and S49C45 glasses, is noticeably more evident in A-glasses and in Ca-richer compositions, in a good agreement with results reported elsewhere [3]. This can be understood considering that higher concentrations of $\mathrm{Ca}^{2+}$ released into the SBF solution [54] and the concomitant increase in $\mathrm{pH}$ favours the precipitation of calcite from the reaction between $\mathrm{Ca}^{2+}$ and $\mathrm{CO}_{3}{ }^{2-}$ available in air [55]. The early ( $4 \mathrm{~h}$ ) appearance of calcite in A-glasses can be attributed to their less polymerised network structures favouring the release of $\mathrm{Ca}^{2+}$ and the cascade of associated reactions leading to the formation of calcite [55]. The same reasoning also explains why calcite was formed for longer immersion time periods, even in the case of $\mathrm{N}$-glasses.

\subsubsection{Evolution of $p H$ (supernatant SBF solutions) and of glass surface compositions}

The $\mathrm{pH}$ curves for $\mathrm{N}-$ glasses appear always above those of the Aglasses, a feature that can be attributed to their higher SSA. A rapid initial raise in $\mathrm{pH}$ from the starting value of 7.4 was registered at $4 \mathrm{~h}$ time point for both $\mathrm{A}-$ glasses and $\mathrm{N}-$ glasses, attributed to the sudden leaching of alkaline $\left(\mathrm{Na}^{+}\right)$and alkaline earth $\left(\mathrm{Ca}^{2+}\right)$ ions from the surface of the glass particles. This was then followed by an overall gradual reversal of this trend between $4 \mathrm{~h}$ and $24 \mathrm{~h}$, probably due to the partial consumption of $\mathrm{Ca}^{2+}$ ions in the Ca-containing phases (HAp and calcite), as confirmed in Fig. 8. The systematic lower $\mathrm{pH}$ variations observed for A-glasses, and for compositions with the lowest calcium contents (Fig. 7), are consistent with the early precipitation of calcite in A-glasses (Fig. 5), particularly noticeable for Ca-richer compositions (Fig. 5(e)). The influence of Ca-content seems to predominate, explaining why the $\mathrm{pH}$ curves measured for $\mathrm{A}$-glasses and $\mathrm{N}$-glasses tend to approach each other with increasing Ca-content, appearing almost superimposed for the S51SC40 composition. The overall decreasing trends in $\mathrm{pH}$ observed between $24 \mathrm{~h}$ and 1 week of immersion might be attributed to the consumption of $\mathrm{Ca}^{2+}$ ions for the precipitation of HAp and calcite, as confirmed by XRD patterns (Fig. 5) and FTIR spectra (Fig. 6), and the gradually increasing surface Ca and P concentrations after $4 \mathrm{~h}$ of immersion (Fig. 8). After 1 week, the systems reach an apparent equilibrium situation, probably due an enhanced hindered dissolution effect exerted by the mineralised surface layer. The acidic glass former species such as $\mathrm{Si}^{4+}$ and phosphate ions remaining in the solution are also likely to cooperate for this apparent constancy of $\mathrm{pH}$ values. Almost similar behaviour was observed for the AP40 glass, calcined at $600^{\circ} \mathrm{C}$, and in both glasses, the dissolution was stabilised at $\mathrm{pH}=8$ after one week of immersion in SBF [56].

\subsection{Biocompatibility and cytotoxicity}

The results of in vitro biocompatibility and cytotoxicity for all tested cell lines are intimately related to the concentrations of alkaline ionic species leached to the culture media by the glasses $[17,43,44]$. This explains why calcium-richer compositions, especially if synthesised by the acetates route and thermally stabilised at $550{ }^{\circ} \mathrm{C}$, are the most cytotoxic (Fig. 9(h-i)).

The available literature reports on the assessment of the biocompatibility and cytotoxicity related to $45 \mathrm{~S} 5$ composition bioactive glasses synthesised by a rapid sol-gel route are scarce. Only a single study [57] was found reporting cytotoxicity tests of a sol-gel derived 45S5 Bioglass ${ }^{\circledast}$ composition, thermally stabilised at $600^{\circ} \mathrm{C}$, towards human dental pulp stem cells, with cytotoxic effects being observed for concentration levels $>0.4 \mathrm{mg} \mathrm{mL}^{-1}$ after 1-7 days [57].

\section{Conclusions}

The synthesis from nitrate precursors under lower $\mathrm{pH}$ environments results in slower condensation reactions, the formation of amorphous glass structures with higher extents of polymerisation, skeletal density, and SSA that favour the in-vitro bio-mineralisation rate.
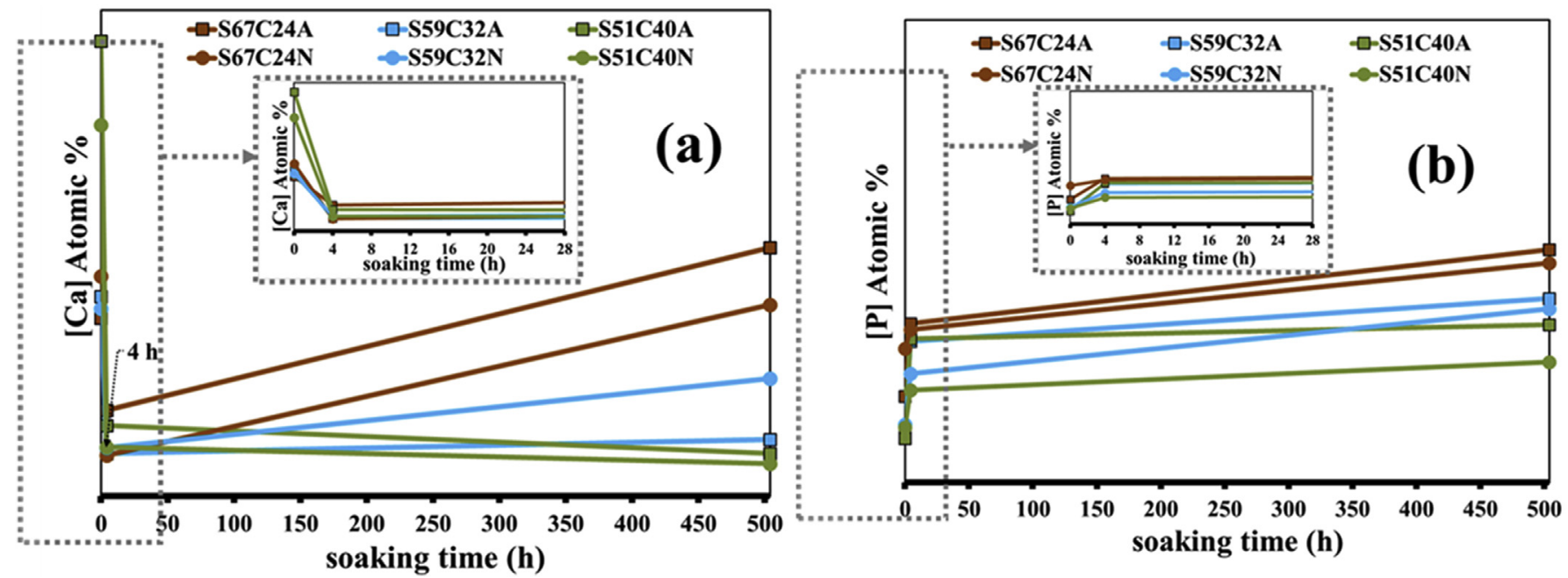

Fig. 8. Atomic surface concentrations of Ca (a) and P (b) species measured by EDS after the indicated immersion time points for selected compositions (S67C24, S59C32, S51C40) of A-glasses and $\mathrm{N}-$ glasses thermally stabilised at $550{ }^{\circ} \mathrm{C}$ and immersed in $\mathrm{SBF}$ for different time periods. 

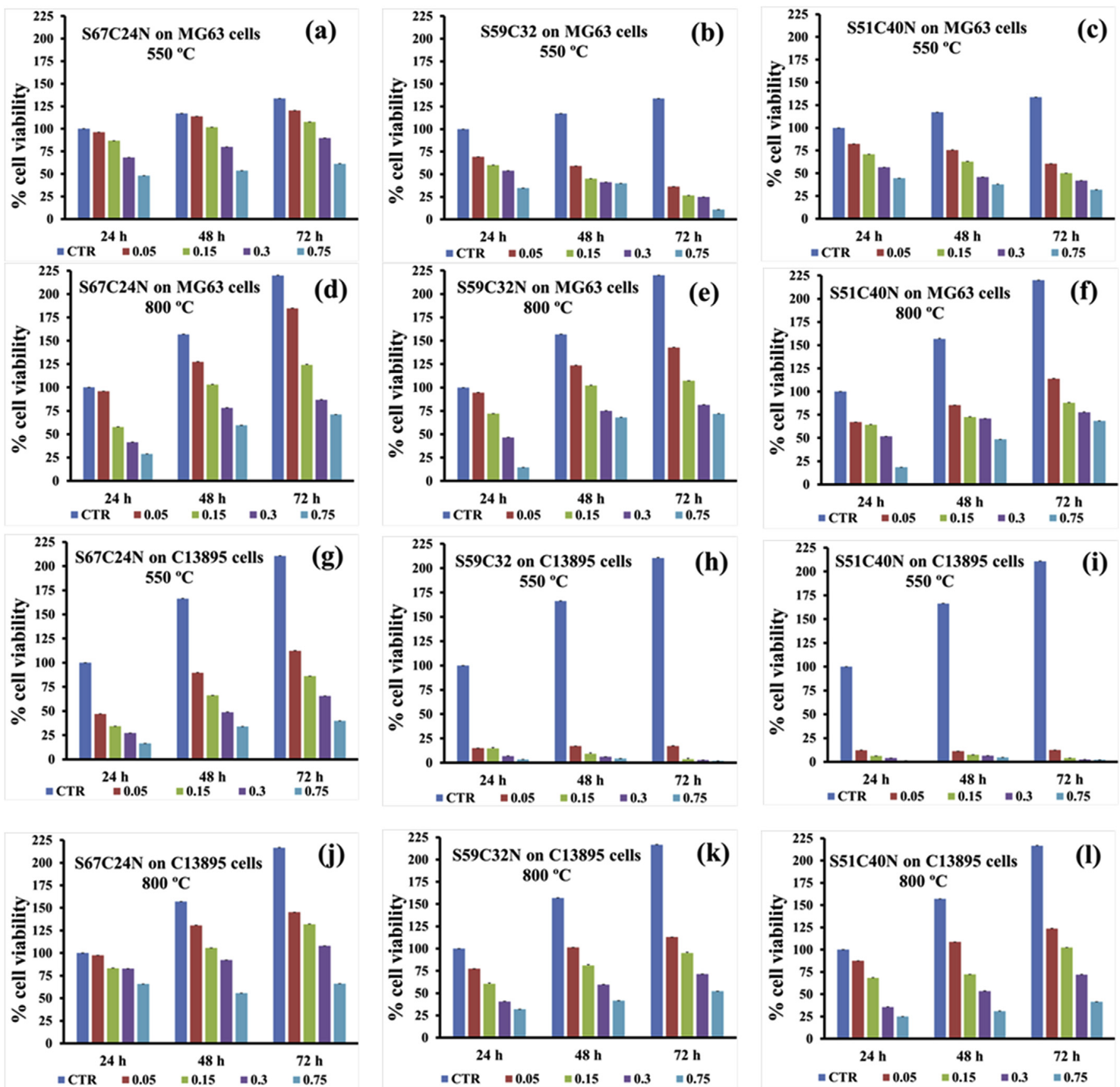

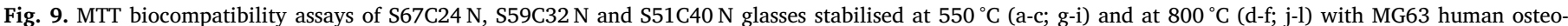

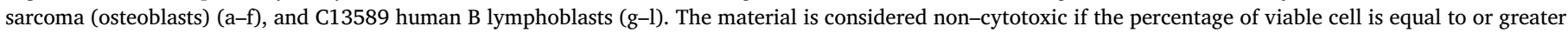
than $70 \%$ of the untreated control. The tested glass powder concentrations $(0.05,0.1,0.3$, and 0.75$)$ are in $\mathrm{mg} \mathrm{mL}^{-1}$.

Being mostly amorphous, A-glasses also contain small amounts of crystalline phases such HAp and silica (coesite), The formation of these phases could be stimulated by the higher $\mathrm{pH}$ environment and the consequent faster condensation reactions, resulting in lower extents of network polymerisation, higher degrees of primary particles agglomeration, closed porosity and lower SSA values. These features favoured the in vitro formation of unwanted calcite $\left(\mathrm{CaCO}_{3}\right)$ phase.

The poor extraction of nitrate residues derived from the high concentrations of nitric acid used as catalyst and its interaction with acetate species is the main drawback of $\mathrm{A}$-glasses. The thermal stabilisation at $550{ }^{\circ} \mathrm{C}$ is insufficient to get rid of nitrate residues. Nevertheless, using different metal salt precursors as the case of acetate and nitrate may enable a reasonable change in the network connectivity, and SSA of the glasses which play an important role in tailoring the bioactivity of the sol-gel glasses.

The biocompatibility is enhanced for samples thermally stabilised at higher temperature $\left(800^{\circ} \mathrm{C}\right)$ and especially for glass compositions richer in silica. The composition S67C24 N is biocompatible with MG63 osteoblasts up to concentration levels of $0.3 \mathrm{mg} \mathrm{mL}^{-1}$

\section{Acknowledgments}

R.C. Pullar wishes to thank the FCT Grant IF/00681/2015 for supporting this work. B. A. E. Ben-Arfa thanks FCT grant BIONANOSCULP PTDC/EPH-PAT/6281/2014 for supporting him during this work. I.E. Palamá thanks the Italian Association for Cancer Research (AIRC) 
through the grant MFAG n. 16803 and Tecnomed (FIRS project of nanotechnology, photonics and precision medicine) for partially supporting this work. This work was developed within the scope of the project CICECO-Aveiro Institute of Materials, FCT Ref. UID/CTM/ $50011 / 2019$, financed by national funds through the FCT/MCTES.

\section{References}

[1] C. Ohtsuki, T. Kokubo, T. Yamamuro, Mechanism of apatite formation on CaOSiO2-P2O5 glasses in a simulated body fluid, J. Non-Cryst. Solids 143 (1992) 84-92.

[2] N.J. Coleman, M. Bellantone, J.W. Nicholson, A.P. Mendham, Textural and structural properties of bioactive glasses in the system CaO-SiO2, Ceram. - Silikaty. 51 (2007) 1-8.

[3] A. Martínez, I. Izquierdo-Barba, M. Vallet-Regí, Bioactivity of a CaO - SiO2 binary glasses system, Chem. Mater. 12 (2000) 3080-3088.

[4] P. Kiran, V. Ramakrishna, M. Trebbin, N.K. Udayashankar, H.D. Shashikala, Effective role of CaO/P2O5 ratio on SiO2-CaO-P2O5 glass system, Ceram. Int. 8 (2017) 279-288.

[5] A. Tilocca, A.N. Cormack, Structural effects of phosphorus inclusion in bioactive silicate glasses, J. Phys. Chem. B 111 (2007) 14256-14264.

[6] M.D. O'Donnell, S.J. Watts, R.G. Hill, R.V. Law, The effect of phosphate content on the bioactivity of soda-lime- phosphosilicate glasses, J. Mater. Sci. Mater. Med. 20 (2009) 1611-1618.

[7] Q.-Z. Chen, Y. Li, L.-Y. Jin, J.M.W.W. Quinn, P.A. Komesaroff, A new sol-gel process for producing Na2O-containing bioactive glass ceramics, Acta Biomater. 6 (2010) 4143-4153.

[8] A.E. Danks, S.R. Hall, Z. Schnepp, The evolution of 'sol-gel' chemistry as a technique for materials synthesis, Mater. Horiz. 3 (2016) 91-112.

[9] M. Sharma, M. Pathak, P.N. Kapoor, The sol-gel method: pathway to ultrapure and homogeneous mixed metal oxide nanoparticles, Asian J. Chem. 30 (2018) 1405-1412.

[10] I. Cacciotti, Bivalent cationic ions doped bioactive glasses: the influence of magnesium, zinc, strontium and copper on the physical and biological properties, J. Mater. Sci. 52 (2017) 8812-8831.

[11] M. Lombardi, L. Gremillard, J. Chevalier, A comparative study between melt-derived and sol-gel synthesized $45 S 5$ bioactive glasses, Key Eng. Mater. 541 (2013) $15-30$.

[12] L.C. Klein, Sol-gel Technology for Thin Films, Fibres, Preforms, Electronics, and Specialty Shapes, Noyes Publications, New Jersey, 1988.

[13] M.a. Fardad, Catalysts and the structure of SiO2 sol-gel films, J. Mater. Sci. 35 (2000) $1835-1841$.

[14] C.J. Brinker, Hydrolysis and condensation of silicates: effects on structure, J. NonCryst. Solids 100 (1988) 31-50.

[15] J. Faure, R. Drevet, A. Lemelle, N. Ben Jaber, A. Tara, H. El Btaouri, et al., A new sol-gel synthesis of $45 S 5$ bioactive glass using an organic acid as catalyst, Mater. Sci. Eng. C 47 (2015) 407-412.

[16] M. Catauro, F. Bollino, R.a.A. Renella, F. Papale, F. Bollino, R.a.A. Renella, et al., Sol-gel synthesis of SiO2-CaO-P2O5 glasses: influence of the heat treatment on their bioactivity and biocompatibility, Ceram. Int. 41 (2015) 12578-12588.

[17] M. Catauro, F. Papale, L. Sapio, S. Naviglio, Biological in fl uence of Ca/P ratio on calcium phosphate coatings by sol-gel processing, Mater. Sci. Eng. C 65 (2016) 188-193.

[18] I. Lebecq, D.F., A. Leriche, C. Follet-Houttemane, Compositional dependence on the in vitro bioactivity of invert or conventional bioglasses in the Si-Ca-Na-P system, J. Biomed. Mater. Res. A 38A (2007) 156-168.

[19] B.A.E. Ben-arfa, I.M.M. Salvado, J.M.F.F. Ferreira, R.C. Pullar, A hundred times faster: novel, rapid sol-gel synthesis of bio-glass nanopowders (Si-Na-Ca-P system, Ca:P = 1.67) without aging, Int. J. Appl. Glass Sci. 8 (2017) 337-343.

[20] B.A.E. Ben-Arfa, I.M.M. Salvado, J.M.F.F. Ferreira, R.C. Pullar, Novel route for rapid sol-gel synthesis of hydroxyapatite, avoiding ageing and using fast drying with a 50fold to 200-fold reduction in process time, Mater. Sci. Eng. C 70 (2017) 796-804.

[21] B.A.E.E.E. Ben-Arfa, I.M.M.M. Salvado, J.R. Frade, R.C. Pullar, Fast route for synthesis of stoichiometric hydroxyapatite by employing the Taguchi method, Mater. Des. 109 (2016) 547-555.

[22] A.L.B. Maçon, T.B. Kim, E.M. Valliant, K. Goetschius, R.K. Brow, D.E. Day, et al., A unified in vitro evaluation for apatite-forming ability of bioactive glasses and their variants, J. Mater. Sci. Mater. Med. 26 (2015) 1-10.

[23] B.A.E. Ben-Arfa, A.S. Neto, I.E. Palamá, I.M. Miranda Salvado, R.C. Pullar, J.M.F. Ferreira, Robocasting of ceramic glass scaffolds: sol-gel glass, new horizons, J. Eur. Ceram. Soc. 39 (2018) 1625-1634.

[24] Y.T. Kokubo T, H. Kushitani, S. Sakka, T. Kitsugi, Solutions able to reproduce in vivo surface-structure changes in bioactive glass-ceramic A-W, J. Biomed. Mater. Res. 24 (1990) 721-734.

[25] International Organization for Standardization, International Organization for Standardization, ISO 10993-5. Biological Evaluation of Medical Devices-Part 5: Tests for in Vitro Cytotoxicity, ISO, Geneve, 20092009.

[26] I. Cacciotti, M. Lombardi, A. Bianco, A. Ravaglioli, L. Montanaro, Sol-gel derived $45 S 5$ bioglass: synthesis, microstructural evolution and thermal behaviour, J. Mater. Sci. Mater. Med. 23 (2012) 1849-1866, https://doi.org/10.1007/s10856012-4667-6.

[27] M. Lombardi, I. Cacciotti, A. Bianco, L. Montanaro, RKKP bioactive glass-ceramic material through an aqueous sol-gel process, Ceram. Int. 41 (2015) 3371-3380.

[28] M. Catauro, E. Tranquillo, R. Risoluti, S. Vecchio, C. Id, Sol-gel synthesis, spectroscopic and thermal behavior study of SiO2/PEG composites containing different amount of chlorogenic acid, Jez. Pol. 10 (2018) 1-12.

[29] L.B. Jonathan, G.L. Turner, Anion distributions in sodium silicate solutions. Characterization by 29Si NMR and infrared spectroscopies, and vapor phase osmometry, J. Phys. Chem. B 101 (1997) 10638-10644.

[30] V. Simon, D. Eniu, A. Gritco, S. Simon, Thermal and spectroscopic investigation of sol-gel derived aluminosilicate bioglass matrices, J. Optoelectron. Adv. Mater. 9 (2007) 3368-3371.

[31] V. Aina, G. Malavasi, A. Fiorio Pla, L. Munaron, C. Morterra, Zinc-containing bioactive glasses: surface reactivity and behaviour towards endothelial cells, Acta Biomater. 5 (2009) 1211-1222.

[32] F. Andersen, L. Brecevic, Infrared spectra of amorphous and crystalline calcium carbonate, Acta Chem. Scand. 45 (1991) 1018-1024.

[33] X. Chatzistavrou, D. Esteve, E. Hatzistavrou, E. Kontonasaki, K.M. Paraskevopoulos, A.R. Boccaccini, Sol-gel fabrication of glass-ceramic composite materials for dental application, Bioceram. Dev. Appl. 1 (2011) 1-4.

[34] H. Aguiar, J. Serra, P. González, B. León, Structural study of sol-gel silicate glasses by IR and Raman spectroscopies, J. Non-Cryst. Solids 355 (2009) 475-480.

[35] L.L.L. Sepulveda, P. Jones, J.R. Hench, In vitro dissolution of melt derived 45 S5 and sol-gel derived 58 S bioactive glasses, Biomed. Mater. Res. 61 (2002) 301-311.

[36] L.L.L. Dasz-Flores, G. Luna-Barcenas, J. Gonzalez-Hernandez, Y.V. Vorobiev, Preparation and optical properties of SiO2 sol-gel made glass colored with carminic acid, J. Sol. Gel Sci. Technol. 33 (2005) 261-267.

[37] P. Innocenzi, Infrared spectroscopy of sol - gel derived silica-based films : a spectramicrostructure overview, J. Non-Cryst. Solids 316 (2003) 309-319.

[38] R.S. Pryce, L.L. Hench, Tailoring of bioactive glasses for the release of nitric oxide as an osteogenic stimulus, J. Mater. Chem. 14 (2004) 2303.

[39] B. Sarker, W. Li, K. Zheng, R. Detsch, A.R. Boccaccini, Designing porous bone tissue engineering scaffolds with enhanced mechanical properties from composite hydrogels composed of modified alginate, gelatin, and bioactive glass, ACS Biomater. Sci. Eng. 2 (2016) 2240-2254.

[40] M. Montazerian, J. Fabián, B. Eftekhari, Sol - gel synthesis, structure, sintering and properties of bioactive and inert nano-apatite - zirconia glass - ceramics, Ceram. Int. 41 (2015) 11024-11045.

[41] F.Z. Ren, Y. Leng, Carbonated apatite, type-A or type-B? Key Eng. Mater. 493-494 (2012) 293-297.

[42] I. Notingher, J.R. Jones, S. Verrier, I. Bisson, P. Embanga, P. Edwards, et al., Application of FTIR and Raman spectroscopy to characterisation of bioactive materials and living cells, Spectros. Int. J. 17 (2003) 275-288.

[43] J. Ge, M. Li, Q. Zhang, C.Z. Yang, P.H. Wooley, X. Chen, et al., Silica aerogel improves the biocompatibility in a poly--caprolactone composite used as a tissue engineering scaffold, Int. J. Polym. Sci. 2013 (2013) 1-7.

[44] S.H. Huang, Y.J. Chen, C.T. Kao, C.C. Lin, T.H. Huang, M.Y. Shie, Physicochemical properties and biocompatibility of silica doped $\beta$-tricalcium phosphate for bone cement, J. Dent. Sci. 10 (2015) 282-290.

[45] F. Baino, E. Fiume, M. Miola, E. Verné, Bioactive sol-gel glasses: processing, properties, and applications, Int. J. Appl. Ceram. Technol. 15 (2018) 841-860.

[46] A.L.B. Maçon, M. Jacquemin, S.J. Page, S. Li, S. Bertazzo, M.M. Stevens, et al., Lithium-silicate sol-gel bioactive glass and the effect of lithium precursor on structure-property relationships, J. Sol. Gel Sci. Technol. 81 (2017) 84-94.

[47] B.A.E. Ben-Arfa, H.R. Fernandes, I.M.M.M. Salvado, J.M.F.F. Ferreira, R.C. Pullar, Effects of catalysts on polymerization and microstructure of sol-gel derived bioglasses, J. Am. Ceram. Soc. 101 (2018) 2831-2839.

[48] A. Mali, A. Ataie, Influence of the metal nitrates to citric acid molar ratio on the combustion process and phase constitution of barium hexaferrite particles prepared by sol-gel combustion method, Ceram. Int. 30 (2004) 1979-1983.

[49] J.M.M. Miller, B. Dunn, J.S.S. Vaentine, J.I.I. Zink, Synthesis conditions for encapsulating cytochrome $\mathrm{c}$ and catalase in SiO 2 sol-gel materials, J. Non-Cryst. Solids 202 (1996) 279-289.

[50] J.R. Jones, L.L. Hench, Factors affecting the structure and properties of bioactive foam scaffolds for tissue engineering, J. Biomed. Mater. Res. B Appl. Biomater. 68 (2004) 36-44.

[51] M.N. Rahamana, Ceramic Processing and Sintering, second ed., Marcel Dekker, inc., New York, 2003.

[52] S. Heidari, T. Hooshmand, B.E. Yekta, A. Tarlani, N. Noshiri, M. Tahriri, Effect of addition of titanium on structural, mechanical and biological properties of $45 \mathrm{S5}$ glass-ceramic, Ceram. Int. 44 (2018) 11682-11692.

[53] L.L. Hench, Bioceramics: from concept to clinic, J. Am. Ceram. Soc. 74 (1991) $1487-1510$.

[54] D. Lukito, J.M. Xue, J. Wang, In vitro bioactivity assessment of 70 (wt.)\% SiO2 -30 (wt.)\% CaO bioactive glasses in simulated body fluid, Mater. Lett. 59 (2005) 3267-3271.

[55] J.M.F.F. Ferreira, S.M. Olhero, A. Kaushal, Is the ubiquitous presence of barium carbonate responsible for the poor aqueous processing ability of barium titanate? J. Eur. Ceram. Soc. 33 (2013) 2509-2517.

[56] I. Cacciotti, G. Lehmann, A. Camaioni, AP40 bioactive glass ceramic by sol-gel Synthesis : in vitro dissolution and and cell-mediated bioresorption, Key Eng. Mater. 541 (2013) 40-50.

[57] S.N.F.M. Noor, N.S.M. Zain, P.Y. Wei, N.S. Azizan, H. Mohamad, Development of sol-gel bioactive glass for hard tissue regeneration, AIP Conf. Proc., 2016, pp. 20016-20017. 